\title{
Performance Analysis of X Band Horn Antennas using Additive Manufacturing Method Coated with Different Techniques
}

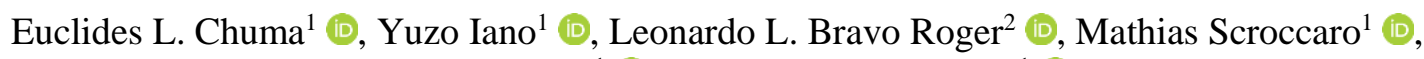 \\ Felipe Frazatto ${ }^{1} \mathbb{D}$, Leandro Tiago Manera ${ }^{1}$ \\ ${ }^{1}$ Department of Communications, School of Electrical and Computer Engineering, University of Campinas - \\ UNICAMP, 13083-852, Campinas-SP, Brazil \\ ${ }^{2}$ School of Technology, University of Campinas - UNICAMP, 13484-332, Campinas-SP, Brazil \\ E-mails: euclides.chuma@ieee.org,yuzo@decom.fee.unicamp.br,leobravo@ft.unicamp.br
}

\begin{abstract}
In this study are analyzed horn antennas to operating at $\mathrm{X}$ band $(8-12 \mathrm{GHz})$ and manufactured by additive manufacturing method (AM). To construct the antennas using AM method was necessary made the structure with acrylonitrile butadiene styrene (ABS) thermoplastic using a 3D printer, and then coated the antennas with conductive surfaces. Were fabricated three antennas with different coated techniques: the first antenna with conductive silver paint, the second antenna using copper tape and the third antenna using copper plated. It is investigated the performances of these antennas in terms of the input reflection coefficient, gain, radiation pattern, weight and compared with the conventional aluminum horn antenna with same dimensions.
\end{abstract}

Index Terms - antenna, 3D printing, additive manufacturing, horn, coated.

\section{INTRODUCTION}

Additive manufacturing (AM) has gained much interest recently because of the ability of rapidly prototype complex three-dimensional (3-D) objects with cost-effective process, including electromagnetic parts like antennas and waveguides [1] - [4]. In AM method the designed object is extruded layer by layer and can use different technologies, such as fused deposition modeling (FDM), stereolithography apparatus (SLA), ceramic stereolithography apparatus (CSLA), microstereolithography apparatus ( $\mu \mathrm{SLA})$, binder jetting (BJ), polymer jetting (PJ), selective laser melting (SLM), and electron beam melting (EBM) [5].

The horn antennas are broadband antennas used for wide band transmit and receive applications and are well known and useful for antenna measurement [6]. These characteristics turn it a good candidate to be manufacture by AM and compare your performance with standard antennas.

Unfortunately, additive manufacturing of metal is not yet available for the consumer market and is costly [7], however there are many types of 3D printers that are commercially available to consumer market able to print on plastics like the acrylonitrile butadiene styrene (ABS) using fused deposition 
modeling (FDM) [5] and then the surface is coated with a conductors like a conductive paint [8] or metal tape [9].

In this study, we printed three identical horn antennas at $\mathrm{X}$ band $(8-12 \mathrm{GHZ})$ using FDM 3D printing with $\mathrm{ABS}$, and so coated with silver conductive paint, with copper tape and with copper plated metallization. A fourth horn antenna was fabricated in aluminum by conventional process and with same internal dimensions to be used to compare with the others horn antennas made with 3D printer. Thus, was possible analyze and compare the performances of these antennas in terms of the input reflection coefficient $\left(\mathrm{S}_{11}\right)$, gain, radiation pattern and weight.

\section{ANTENNA DESIGN}

The dimensions of the horn antenna can be calculated by equations given in the literature [10]. With the initial dimensions calculated, the optimization was performed using Ansys HFSS. The curve horn is exponentially fitted to the dimensions of a waveguide WR90 meet the free space aperture smoothly. The thickness of the external walls is $5.5 \mathrm{~mm}$, which is physically robust enough for structural stability. The dimensions of the antenna are shown in Fig. 1.
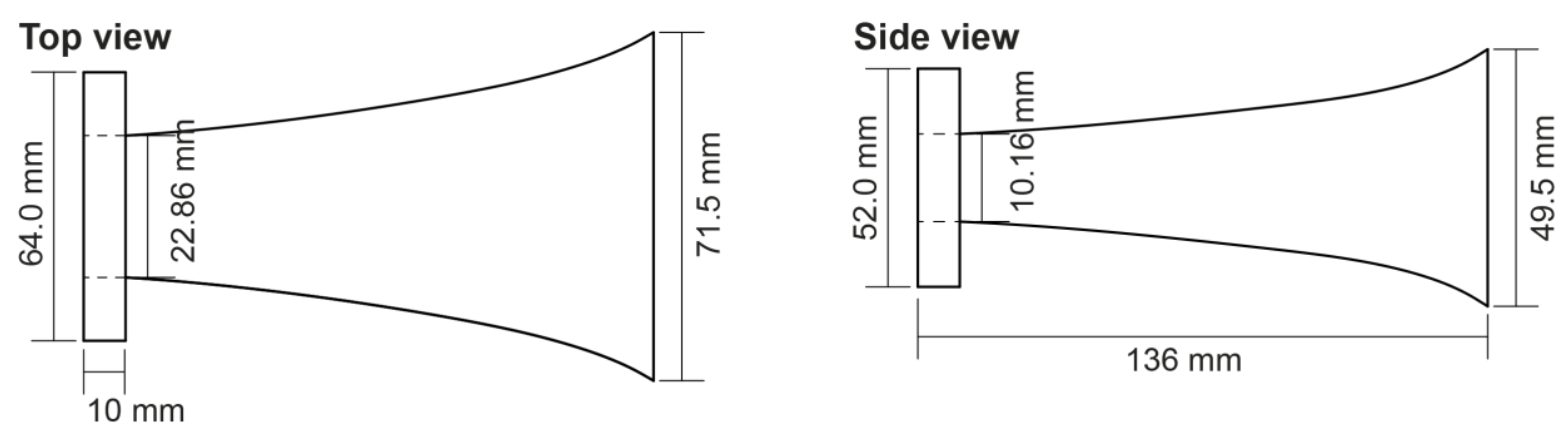

Fig. 1. Dimensions of the fabricated horn antennas.

\section{ANTENNA FABRICATION}

A CAD-model with antenna dimensions was drawn and saved in STL extension to be printed in a 3D printer using FDM technique. The total time spent to print each horn in ABS was approximately 7 hours. The 3D printer used was a Sethi3D AiP with resolution of $0.2 \mathrm{~mm}$.

The ABS used in the antenna is a common thermoplastic polymer with green color and melting temperature of $245^{\circ} \mathrm{C}$. The relative permittivity of ABS is $\sim 2.8$ and the loss tangent $\sim 0.02$ [11]. Use ABS like structure to the antenna not is a new idea and was used in others projects of antennas made in 3D printer [12]-[14].

The interior of the first horn was coated with one layer with $0.025 \mathrm{~mm}$ of thickness using single component epoxy AA-DUCT AD1 from Atom Adhesives [15] that was formulated with pure silver power combined with organic binders and solvents. This type of conductive paint is used in diversified applications as microwave EMI, RFI shielding, waveguides, etc, and have a sheet 
resistivity of 10-12 $\mathrm{m} \Omega /$ square. The horn antenna painted with silver paint is shown in Fig. 2(A).

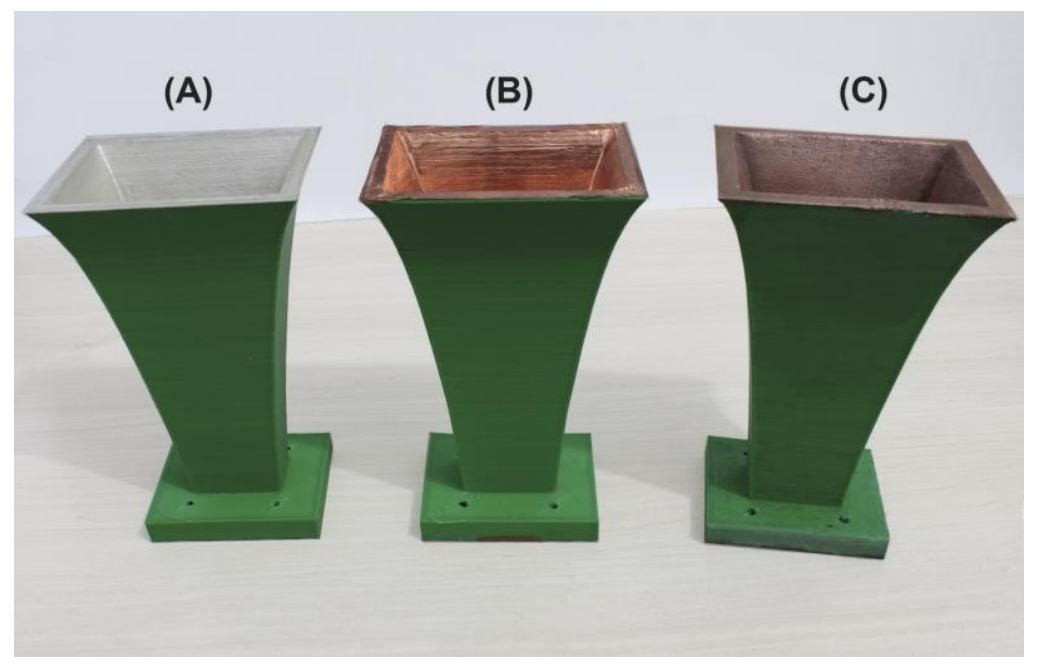

Fig. 2. Horn antennas: (A) silver paint, (B) copper tape, and (C) copper plated.

The interior of second horn was coated with $3 \mathrm{M}^{\mathrm{TM}}$ conductive copper coil tape 3313 with $0.076 \mathrm{~mm}$ total thickness and designed to meet a wide variety of EMI and RFI industrial and electrical applications [16]. The horn antenna coated with copper tape is shown in Fig. 2(B).

The third ABS horn was platted with copper and to make the plating process firstly the ABS horn was coated with the MG Chemicals 838AR Total Ground TM Carbon Conductive Coating [17] that have strong adhesion to ABS to create a conductive surface. After, copper electroplating method was used to create the copper plated in the interior of the horn with a thickness of $0.15 \mathrm{~mm}$. Fig $2 \odot$ shows the horn antenna with copper plated.

\section{MEASUREMENTS AND Results}

The antenna was measured utilizing a HP X281A coaxial WR90 waveguide adapter as shown in Fig. 3. The same coaxial waveguide adapter was used in all measurements to ensure that all antennas had the same excitation.

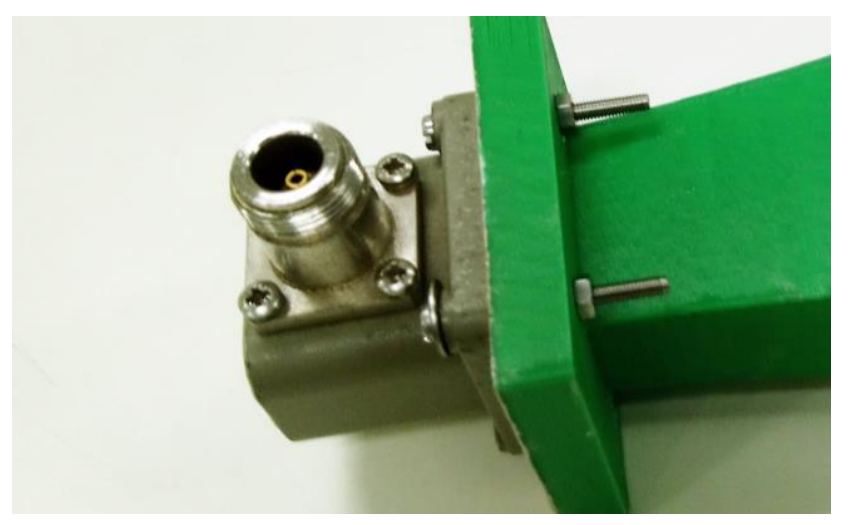

Fig. 3. Coaxial waveguide adapter connected to antenna. 
The reflection coefficient $S_{11}$ of horn antennas using the coaxial waveguide adapter was measured using the Anritsu MS4644B vector network analyzer (VNA). The Fig. 4 shows the $S_{11}$ measurements results.

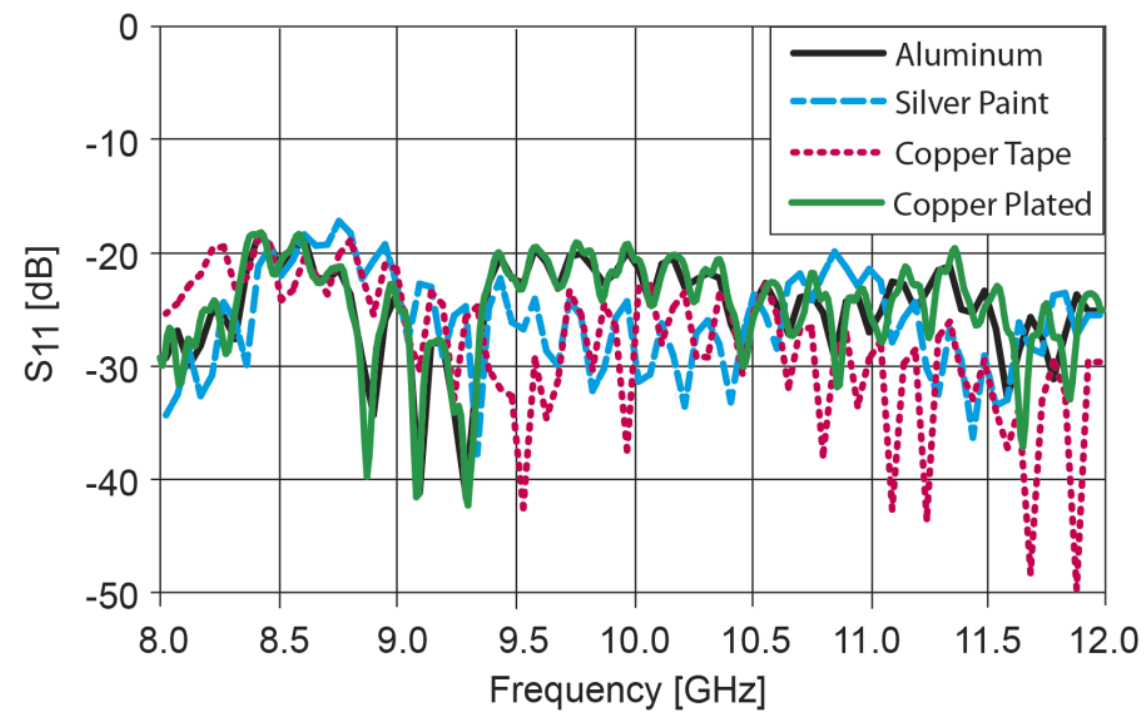

Fig. 4. Measured reflection coefficients $S_{11}$ of horn antennas.

As can be seen in Fig. 4, all antennas exhibited reflection coefficients below -17 dB over complete $\mathrm{X}$ band, which guarantees a good impedance matching in frequency range at $8-12 \mathrm{GHz}$.

To measured the gain of horn antennas was used a microwave signal generator Anritsu MG3694C connected to a Narda model 640 standard gain horn antenna as the reference antenna in transmission, and in the side receiver was used a Keysight N9010B EXA signal analyzer connected to fabricated horn antennas. The Fig. 5 shows the measured gains of the antennas.

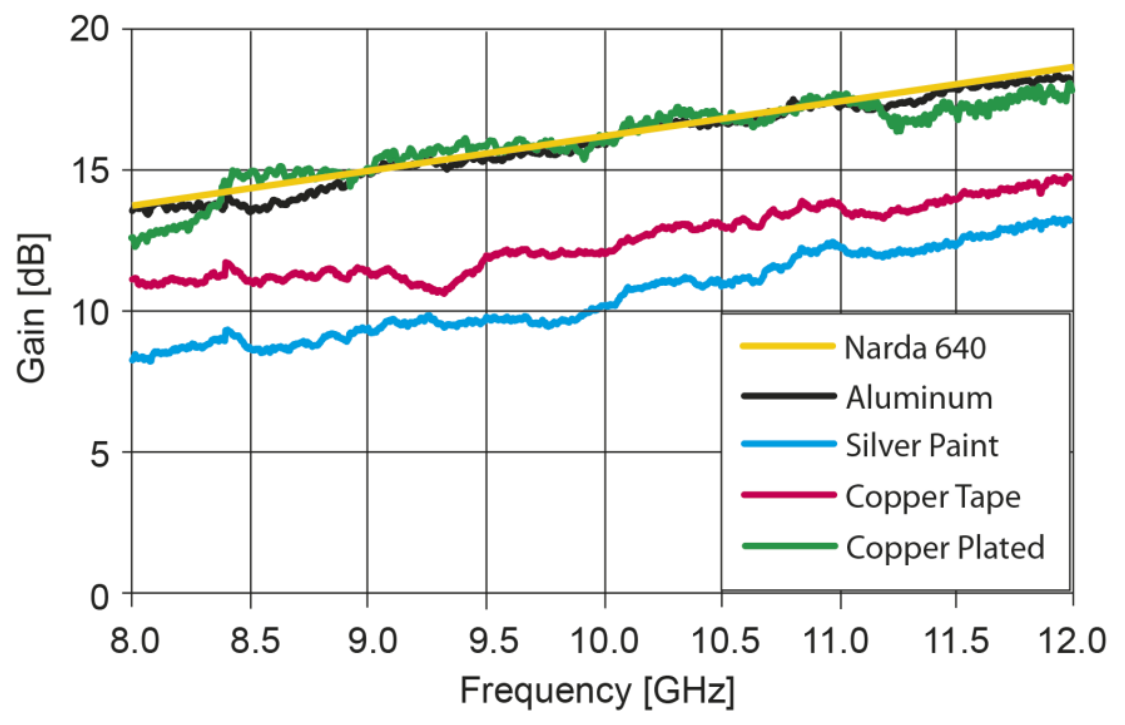

Fig. 5. Measured gains of horn antennas. 
The results of measured gains of horn antennas shows that the 3D ABS copper plated and aluminum horn antennas have a gain similar to Narda model 640 standard gain horn, between $14.7 \mathrm{~dB}$ and $17.7 \mathrm{~dB}$ [18]. The horn antenna coated with copper tape has a lower gain than copper plated horn antenna but between $10.9 \mathrm{~dB}$ and $14.7 \mathrm{~dB}$. And the silver painted horn antenna has a gain between 8.2 $\mathrm{dB}$ and $13.2 \mathrm{~dB}$.

The radiation patterns of the horn antennas at $10 \mathrm{GHz}$ (center of $\mathrm{X}$ band) are given in Fig. 6. As can be seen, the main beam is clearly formed and matches the expected results to horn antennas.
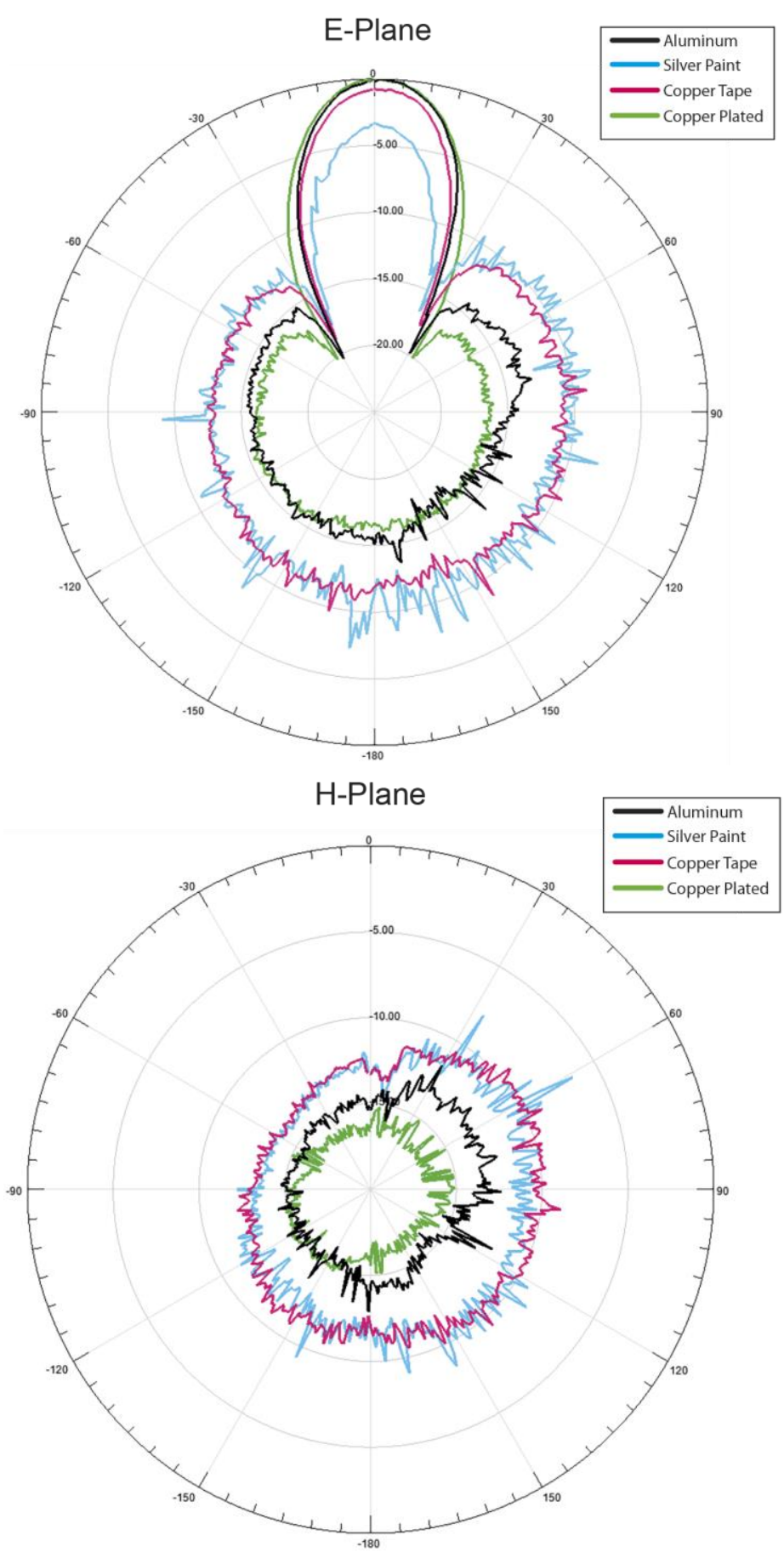

Fig. 6. E-plane and H-plane radiation patterns of the horn antennas. 
The lower gain and directivity in the horn coated with silver paint is as expected, because of the conductivity of silver paint is lower than the copper tape, copper plated and aluminum.

The additive manufacturing method with 3D printing using FDM technique has a drawback that is rough surface finish. The Fig. 7 shows the details of the surface of horns coated with silver paint, copper tape and copper plated.
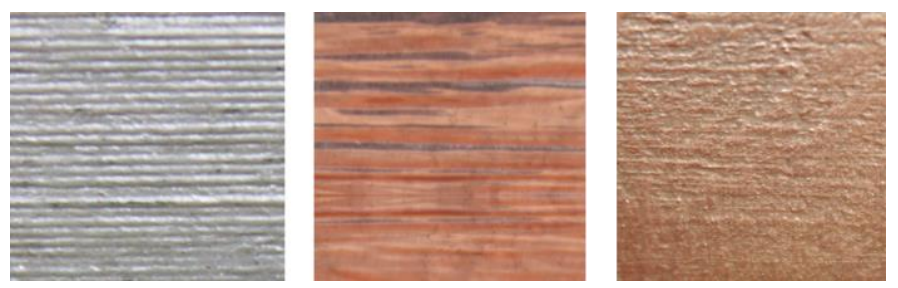

Fig. 7. Details of surface of the horns coated with silver paint, copper tape and copper plated.

If the surface roughness of an electromagnetic component is of the order of the skin depth, so the performance can be degraded [19]. But in both 3D printed horn antennas the surface roughness are much higher than their skin depth for the operating wavelength. It is also important to mention that the surface roughness increases the random scattering of electromagnetic waves that increase the RF resistance, which reduces the gain of the antenna [20] [21].

One of the good points of using horn antennas with structures built in a 3D printer with ABS is the weight being lighter than the horn antennas built by the conventional process. The Table I shows the weights of horn antenna used in this study, including a commercial horn antenna Narda model 640 which has similar dimensions to fabricated horn antennas.

TABLE I. WEIGHT OF HoRn ANTENNAS

\begin{tabular}{cccccc}
\hline & $\begin{array}{c}\text { Horn in ABS with } \\
\text { Silver Paint }\end{array}$ & $\begin{array}{c}\text { Horn in ABS with } \\
\text { Copper Tape }\end{array}$ & $\begin{array}{c}\text { Horn in ABS with } \\
\text { Copper Plated }\end{array}$ & $\begin{array}{c}\text { Horn in } \\
\text { Aluminum }\end{array}$ & $\begin{array}{c}\text { Narda } \\
\mathbf{6 4 0}\end{array}$ \\
\hline $\begin{array}{c}\text { Weight } \\
\text { (g) }\end{array}$ & 60 & 61 & 82 & 645 & 230 \\
\hline
\end{tabular}

\section{CONCLUSIONS}

Three horn antennas made in 3D printer and coated with silver paint, copper tape and copper plated were fabricated and compared with a traditional aluminum horn antenna with same dimensions. The measurement results of the antennas were made in $\mathrm{X}$ band $(8-12 \mathrm{GHz})$ and compared in terms of the input reflection coefficient $S_{11}$, gain, radiation pattern and weight.

It was observed that the horn antennas fabricated by AM (3D printing by FDM) and coated with silver paint and copper tape have a lower gain than the traditional antenna in aluminum, and the horn antenna coated with copper plated by electroplating method has gain similar to aluminum antenna.

The horn antenna plated with copper has best performance that the horn antenna coated with silver paint and copper tape because of higher conductivity in copper plated than in the silver paint and Brazilian Microwave and Optoelectronics Society-SBMO received 30 May 2018; for review 21 June 2018; accepted 4 Apr 2019 
because of the thickness of copper plated is higher than copper tape.

The AM method using ABS and coated with silver paint, copper tape or copper plated is lighter than traditional aluminum horn antennas. All three horn antennas showed in this work and made with 3D printer and coated with different techniques can be used in $\mathrm{X}$ band, but with different performances, mainly in gain parameter.

\section{REFERENCES}

[1] A. I. Dimitriadis, T. Debogović, M. Favre, M. Billod, L. Barloggio, J. Ansermet, E. Rijk, "Polymer-Based Additive Manufacturing of HighPerformance Waveguide and Antenna Components," Proceedings of the IEEE, vol. 105, no. 4, pp. $668-676,2017$.

[2] M. Kilian, C. Hartwanger, M. Schneider, M. Hatzenbichler, "Waveguide components for space applications manufactured by additive manufacturing technology," IET Microwaves, Antennas \& Propagation - Special Issue: Microwave Components and Antennas Based on Advanced Manufacturing Techniques, 2017.

[3] S. Verploegh, M. Coffey, E. Grossman, Z. Popovi'c, "Properties of 50-110-GHz Waveguide Components Fabricated by Metal Additive Manufacturing," IEEE Transactions on Microwave Theory and Techniques, vol. 65, no. $12,2017$.

[4] E. Laplanche, W. Feuray, J. Sence, A. Perigaud, et al., "Additive manufacturing of low cost and efficient proof of concepts for microwave passive components," IET Microwaves, Antennas \& Propagation - Special Issue: Microwave Components and Antennas Based on Advanced Manufacturing Techniques, 2017.

[5] B. Zhang, Y. X. Guo, H. Zirath, Y. P. Zhang, "Investigation on 3-D-Printing Technologies for Millimeter-Wave and Terahertz Applications," Proceedings of the IEEE, vol. 105, no. 4, 2017.

[6] American National Standard for Electromagnetic Compatibility - Radiated Emission Measurements in Electromagnetic Interference (EMI) Control - Calibration of Antennas (9 kHz to $40 \mathrm{GHz})$, ANSI C63.5-1998, 1998.

[7] M. Dionigi, C. Tomassoni, G. Venanzoni, R. Sorrentino, "Simple High-Performance Metal-Plating Procedure for Stereolithographically 3-D-Printed Waveguide Components," IEEE Microwave and Wireless Components Letters, vol. 27, no. 11, 2017.

[8] A. Périgaud, S. Bila, O. Tantot, N. Delhote, and S. Verdeyme, "3D printing of microwave passive components by different additive manufacturing technologies," in Proc. IEEE MTT-S Int. Microw. Workshop Ser. Adv. Mater. Process. RF THz Appl. (IMWS-AMP), pp. 1-4, 2016.

[9] O. H. Kwon, W. B. Park, S. Lee, J. M. Lee, Y. M. Park, K. C. Hwang, "3D-Printed Super-Wideband Spidron Fractal Cube Antenna with Laminated Copper," Applied Sciences, vol.7, pp. 979, 2017.

[10] C.A. Balanis, Antenna Theory Analysis and Design, 3rd ed, John Wiley \& Sons, 2005.

[11] B. Riddle, J. Baker-Jarvis, J. Krupka, "Complex Permittivity Measurements of Common Plastics Over Variable Temperatures," IEEE Transactions on Microwave Theory and Techniques, vol. 51, no. 3, 2003.

[12] J. S. Chieh, B. Dick, S. Loui, J. D. Rockway, "Development of a Ku-Band Corrugated Conical Horn Using 3-D Print Technology," IEEE Antennas and Wireless Propagation Letters, vol. 13, 2014.

[13] A. Genc, I. B. Basyigit, T. Goksu, S. Helhel, "Investigation of the Performances of X-Ku Band 3D Printing Pyramidal Horn Antennas Coated with the Different Metals", 10th International Conference on Electrical and Electronics Engineering (ELECO), 2017.

[14] G. Huang, S. Zhou, C. Sim, T. Chio, T. Yuan, "Lightweight Perforated Waveguide Structure Realized by 3-D Printing for RF Applications," IEEE Transactions on Antennas and Propagation, vol. 65, no. 8, 2017.

[15] "https://www.atomadhesives.com/TDS/AA-DUCT-AD1-TDS-1-PART-LOW-COST-HEAT-DRY-ELECTRICALLYCONDUCTIVE-SILVER-EPOXY-ADHESIVE.pdf", accessed 17 March 2018.

[16] "https://www.3m.com/3M/en_US/company-us/all-3m-products/ /3M-Conductive-Copper-FoilTape3313/?N=5002385+3293242553", accessed 17 March 2018.

[17] "https://www.mgchemicals.com/products/emi-and-rfi-shielding/acrylic-conductive-coatings-ar-series/838artotalground-carbon-conductive-coating ", accessed 17 March 2018.

[18] "https://nardamiteq.com/docs/WAVEGUIDEHORNANTENNAS_STANDARD_GAIN_HORNS_2.60_TO_40_GHZ. PDF", accessed 17 March 2018

[19] S. P. Morgan Jr., "Effect of Surface Roughness on Eddy Current Losses at Microwave Frequencies," Journal of Applied Physics, vol. 20, pp. 352, 1949.

[20] C. R. Garcia, R. C. Rumpf, H. H. Tsang, J. H. Barton, "Effects of extreme surface roughness on 3D printed horn antenna", Electronics Letters, vol. 49, no. 12, 2013.

[21] D. Shamvedi, O. J. McCarthy, E. O'Donoghue, P. O'Leary, R. Raghavendra, "Improved Performance of 3D Metal Printed Antennas through Gradual Reduction in Surface Roughness," International Conference on Electromagnetics in Advanced Applications (ICEAA), 2017. 